\title{
FOREWORD
}

\section{Special Issue: Advances in the Economic Analysis of Food System Drivers and Effects}

\section{Stephan J. Goetz, and Edward C. Jaenicke co-editors}

National interest in the effects of the U.S. food system has risen to such a level that the Institute of Medicine (IOM) and National Research Council (NRC) of the National Academies was compelled recently to publish A Framework for Assessing Effects of the Food System (IOM/NRC 2015), focusing on health, environmental, and economic and social variables. While providing a useful framework, the volume stopped short of actually carrying out studies to validate or test the assumptions of the framework. In addition to having measurable societal effects, food systems are also being affected by powerful secular forces that range from rising income inequality, consolidation and rationalization in retailing, consumer preferences for local and regional foods, to changes in climate and competition for land associated with urbanization. In parallel, an expanding "food movement" has emerged that, with little formal or rigorous analysis, has become highly critical of the food system and its consequent health, environmental, and economic and social effects.

Most if not all of these forces and their consequences can be analyzed using the tools and methods of economics. Bringing economic analysis to the vocal criticisms of the current food system can deepen the debate, help bridge divergent views, and enhance the long-term sustainability of the entire food system. A range of complex and interrelated socioeconomic, environmental, and health-related issues arise in this context, which can only be addressed effectively from a comprehensive systems perspective. Yet most existing studies proceed to address only certain aspects of these systemic problems, and none comprehensively addresses health, environmental, social and economic dimensions.

Stephan J. Goetz is Professor of Agricultural and Regional Economics and Director of the Northeast Regional Center for Rural Development. Edward C. Jaenicke is Professor of Agricultural Economics; both are in the Department of Agricultural Economics, Sociology and Education at Penn State University. Correspondence: Stephan Goetz " 207C Armsby Building " Penn State, University Park " PA 16802-5602 -Email: sgoetz@psu.edu

USDA NIFA funding under grant no. 2018-67023-27691 is gratefully acknowledged.

Agricultural and Resource Economics Review 48/3 (December 2019) 361-364

(C) The Author(s) 2019. This is an Open Access article, distributed under the terms of the Creative

Commons Attribution licence (http://creativecommons.org/licenses/by/4.0/), which permits unrestricted re-use, distribution, and reproduction in any medium, provided the original work is 
Although it was hardly able to solve all problems related to the food system, the NIFA-funded conference held on June 9-10, 2018, in Philadelphia, in conjunction with the NAREA annual conference, sought to begin to lay the initial groundwork for addressing this challenge by bringing researchers from different disciplines together and providing them with a framework they can use to start to think about these interrelated issues. We considered a range of issues related to and affecting the food system, and we provided a forum for scientists who often work in silos to consider how their efforts may leverage and be leveraged by the work of other scientists - and in the process producing more system-wide and effective solutions to problems. By bringing researchers with divergent perspectives and methodological approaches to the discussion, we can begin the process of reaching interdisciplinary solutions.

Specifically, the conference sought to convene recognized and emerging experts to present, debate, and advance research on the frontiers of food system drivers and effects, across a wide range of issues. Presentations included both technical research as well as results translated for lay audiences (policy makers, practitioners). At least one session was devoted to assessment of current data and future data needs. We also encouraged discussion among policymakers, practitioners, and scientists, including feedback from policy makers and practitioners to scientists, with the goal of identifying research gaps to be addressed in the future. Audience participation was facilitated and encouraged. This included a round-table dialogue towards the end of the conference. Lastly, a key goal was to ensure additional dissemination of conference results through this special issue of the Agricultural and Resource Economic Review, published by NAREA and Cambridge University Press, as well as publication of summaries in the NERCRD's newsletter and on its website. Funding by NIFA is gratefully acknowledged.

The first three papers consider optimal food hub locations in space, a farm to school supply chain, and willingness-to-pay (WTP) for local broccoli. In particular, in their work entitled "Embedding Economies of Scale Concepts in the Model of Optimal Locations of Fresh Produce Aggregation Hubs" Ge et al. (2019) use a mixed integer linear programming model to find optimal hub locations in space that minimize assembly costs as well as those of firsthandlers of produce. A novelty of this work is that it introduces four annual production and consumption seasons into the model; this allows for greater realism in terms of when and where crops mature and are harvested across the different regions of the U.S. A second innovation of this work is that it simulates scale economies at the produce hub level. This model thus builds on a longer line of related simulation studies at the Northeast Regional Center for Rural Development, starting with Etemadnia et al. (2015). The resulting simulated hub optimal locations are substantially different than those based on non-seasonal models lacking scale economies. This refers to where the hubs are located, their respective sizes and their optimal number. 
Fitzsimmons and O'Hara (2019), in “Market Channel Procurement Strategy and School Meal Costs in Farm-to-School Programs" make use of a novel dataset to assess whether the choice of market channel affects the overall costs of meals served in school cafeterias, using qualitative comparisons. This is important to the common perception that local foods are for various reasons more costly per unit than foods delivered through established institutional buyers. The results suggest that schools are more likely to report lower costs when foods are sourced locally. The authors also report that the number of farmers engaged in direct marketing within a community has a positive effect on the likelihood that foods entering school cafeterias are sourced locally.

Fan et al. (2019) conduct a WTP study of locally purchased broccoli, along with an assessment of quality perception. One of their contributions is that they control for quality perceptions of local vs. non-local foods among the population surveyed. In blind taste tests they find that a high-quality California variety of broccoli is rated more highly than either of two newer broccoli varieties that were developed and grown locally in New York. This differential rating refers to both taste and appearance of the product, in blind quality tests. Perhaps most significantly, despite these differences, consumers show a willingness to pay more for the locally grown products than the import, once they learn that they are grown locally. Thus, the authors conclude that the characteristic of being locally grown not only raises consumers' WTP but also how they perceive the quality of the food.

The next three papers investigate "gaps" of various types: i.e., the gap between the per-meal value of Supplemental Nutrition Assistance Program (SNAP) benefits and the county-specific cost of a meal; the gap between actual and recommended dietary fiber intake levels; and the gap between actual agricultural production (in Northern New England) and the productive capacity.

Gundersen, Waxman, and Crumbaugh (2019) examine the relationship between the level of benefits provided under SNAP and the cost of the average meal in each U.S. county. The authors find that the average cost of a meal for food-secure low-income households is $\$ 2.31$, which is substantially higher than the maximum SNAP benefit level per meal of $\$ 1.84$. Thus, the authors find an average SNAP meal gap of about 24 percent. Filling this gap could reduce food insecurity by $50.9 \%$, according to the authors. This analysis represents a new look at the SNAP program, and readers, even those already familiar with food assistance policies, may find the concept of the SNAP meal gap and the empirical results to be surprising.

For the average American, actual dietary fiber intake of 16 grams per day falls substantially short of the recommend level of 25 grams per day. New research by Senia, Dharmasena, and Capps (2019) shows that this gap is wider for lowincome households. In other words, the cost of a fiber-rich diet, determined by the prices of particular products is an important factor in the dietary fiber gap. Thus, lowering the price of fiber-rich foods, potentially achieved through price subsidies for fruits and vegetable purchases of 20 percent, could help increase 
dietary fiber intake. However, the authors ultimately find that these subsidies would not come close to closing the gap with the recommended levels.

Werner et al. (2019) shine their lens on the Northern New England states of New Hampshire, Vermont, and Maine to undertake a four-part investigation that links the region's productive potential, supply constraints, consumers' WTP for local foods, and the role of intermediaries. In the Northern New England region, the authors find that parts of Maine have productive capacities of between 45 and 60 percent (of their potential). On the other hand, parts of Vermont have lower productive capacities, and New Hampshire lower still. Policies aimed at expanding local production to lower the capacity gap must consider both supply-side constraints, such as labor shortages and difficulties of land conversion, and demand-side constraints, such as highly variable willingness to pay estimates for local produce. The authors' results provide a few direct insights applicable to other regions, and because their approach is systematic, it can be easily replicated elsewhere.

\section{References}

Etemadnia, H., S.J. Goetz, P. Canning, and M. Sadegh Tavallalid. 2015. “Optimal wholesale facilities location within the fruit and vegetables supply chain with bimodal transportation options: An LP-MIP heuristic approach." European Journal of Operational Research 244(2): 648-661.

Fan, X., M.I. Gomez, and P. Coles. 2019. "Willingness to Pay, Quality Perception, and Local Foods: The Case of Broccoli." Agricultural and Resource Economics Review 48(3): 1-19.

Fitzsimmons, J., and J. O'Hara. 2019. "Market Channel Procurement Strategy and School Meal Costs in Farm to School Programs." Agricultural and Resource Economics Review 48(3): 1-26.

Ge, H., P. Canning, S.J. Goetz, A. Perez, and J. Li. 2019. "Embedding Economies of Scale Concepts in Models of Optimal Fresh Produce Aggregation Hubs Locations." Agricultural and Resource Economics Review 48(3): 1-23.

Gundersen, C., R. Waxman, and A. Crumbaugh. 2019. "An Examination of the Adequacy of Supplemental Nutrition Assistance Program (SNAP) Benefit Levels: Impacts on Food Insecurity." Agricultural and Resource Economics Review 48(3).

Institute of Medicine and National Research Council. 2015. A Framework for Assessing Effects of the Food System. Washington, DC: The National Academies Press. https://doi.org/10. $17226 / 18846$.

Senia, M., S. Dharmasena, and O. Capps. 2019. “Can Dietary Fiber Intake be Increased through Nutritional Education and through Subsidies on Selected Food Products?" Agricultural and Resource Economics Review 48(3): 1-25.

Werner, S., S. Lemos Jr., A. Mcleod, J. Halstead, T. Gabe, J.C. Huang, W. Shi, L. Harris, J. McConnon, and C.L. Liang. 2019. "Prospects for New England Agriculture: Farm to Fork." Agricultural and Resource Economics Review 48(3). 